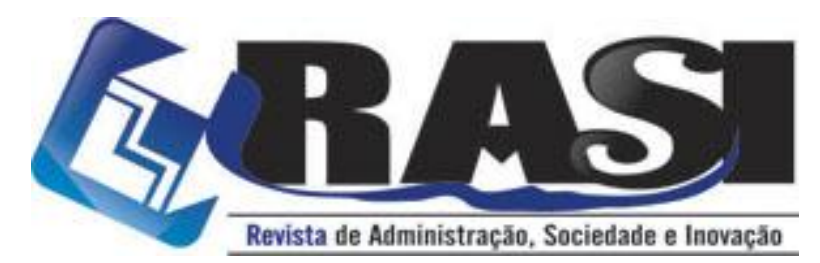

http://www.rasi.uff.br

RASI, Volta Redonda/RJ, v. 1, n. 1, pp. 70-83, Jul./Dez. 2015.

\title{
Investigação da Política Municipal de Comendador Levy Gasparian de Combate à Dengue
}

Patricia Fernanda dos Santos de

Loureiro Nunes - Universidade Federal Fluminense - patricianunes2315@gmail.com

Yuna Souza dos Reis da Fontoura - Fundação Getúlio Vargas (FGV-EBAPE)

Resumo: Endêmica no Brasil e problema de saúde pública, a dengue é combatida a nível local através do Programa Municipal de Combate a Dengue, tema do presente trabalho. O objetivo é analisar a política realizada no município de Comendador Levy Gasparian, os resultados que vem alcançando e principais dificuldades. Para a obtenção de dados foi realizada pesquisa em documentos produzidos no município e entrevistas com os responsáveis pela execução da política. Os resultados encontrados demonstram adequação à diretriz nacional, destacando a necessidade de capacitação dos profissionais e conscientização da população.

Palavras-Chave: Política de Combate à Dengue, Programa Municipal de Combate à Dengue, Comendador Levy Gasparian.

\section{Universidade \\ U1口. Federal \\ Fluminense}

R. Desembargador Ellis Hermydio Figueira, 783, Bloco A, sl. 218, Aterrado.

27213-415 - Volta Redonda, RJ - Brasil

www.uff.br

Copyright (C) 2015 RASI. Todos os direitos, até mesmo de tradução, são reservados. É permitido citar parte de artigos sem autorização prévia, desde que seja identificada a fonte. 


\section{Investigação da Política Municipal de Comendador Levy Gasparian de Combate à Dengue}

\section{Introdução}

Considerada uma das mais relevantes doenças reemergentes transmitidas por artrópodes $^{1}$, a dengue ${ }^{2}$ alcançou notoriedade ao vitimar um grande número de brasileiros desde a primeira epidemia ocorrida no país em 1986, o que fez a doença se elevar à categoria de problema de saúde pública (BRAGA \& VALLE, 2007a). Dessa forma, o Estado criou mecanismos de prevenção e combate ao vetor transmissor do mosquito (com alguns insucessos) e em 2002, após a realização do Seminário Internacional para avaliar as ações contra a dengue foi implantado o Programa Nacional de Controle da Dengue (PNCD), que com ações voltadas à informação e mobilização da população, detecção precoce de surtos da doença, trabalho de campo sistemático e ação intensiva do poder público na eliminação de criadouros conseguiu reduzir em 73,3\% os casos da doença no primeiro ano de atuação (SILVA, 2008).

Os primeiros registros de dengue no Brasil datam de 1946, mas somente a partir de 1986 a doença ganha destaque como epidemia, tornando-a endêmica no país com reincidência de períodos epidêmicos. Novas epidemias ocorreram nos anos de 1990, 1997 e 2001 em alguns casos relacionados à introdução de novos tipos de vírus da doença. $\mathrm{O}$ combate à doença foi sistematizado a partir do século $\mathrm{XX}$, sendo a primeira campanha pública realizada no Rio de Janeiro por Oswaldo Cruz que instituiu brigadas sanitárias com o objetivo de detectar casos de febre amarela e eliminar focos de Aedes aegypti (BRAGA \& VALLE, 2007a).

A Superintendência de Campanhas de Saúde Pública (Sucam) foi criada em 1967 para controlar o combate à malária e febre amarela devido à confirmação da reintrodução do vetor em território nacional, e em 1973 foi efetuada sua erradicação no Brasil. Todavia essa situação não durou muito já que devido a falhas de vigilância epidemiológica e mudanças causadas pela urbanização em 1976 a doença volta a ser um problema, culminando na criação de programas como o Programa Nacional de Controle da Febre amarela e Dengue (PNCFAD) focados na erradicação do vetor (BRAGA \& VALLE, 2007a).

Em 2001 com o objetivo de controle do vetor, foi implantado o Plano de Intensificação das Ações de Controle da Dengue (PIACD) que enfatizou municípios

\footnotetext{
${ }^{1}$ Artrópodes são pertencentes ao Filo Arthropoda, constituindo o maior grupo de organismos quanto ao número de espécies. Possuem o corpo segmentado em cabeça, tórax e abdome ou cefalotórax e abdome com simetria bilateral, patas ou apêndices articulados e exoesqueleto formado por quitina (BRASIL, 2006).
}

\footnotetext{
${ }^{2}$ Nesse trabalho o enfoque está na doença dengue, portanto será utilizada a referência 'a dengue'.
} 
com maior infestação pelo mosquito, e em 2002 foi criado o Programa Nacional de Controle da Dengue que seguiu algumas propostas do PIACD e destacou a necessidade de mudança nos planos anteriores (BRAGA \& VALLE, 2007a).

Infestando preferencialmente países de clima quente e úmido, a dengue é considerada uma doença tropical e pode ser transmitida tanto pelo Aedes aegypti quanto pelo Aedes albopictus sendo registrada no Brasil apenas a transmissão pelo primeiro vetor, visto que o segundo não apresenta um comportamento domiciliar (SILVA, 2008), mas acredita-se que possa contribuir na transmissão de febre amarela (BRAGA \& VALLE, 2007 b).

Considerando o contexto climático e social do Brasil e o histórico de epidemias ocorridas no país, percebe-se a dificuldade de controlar o surgimento de novos casos mesmo com a ação contínua do PMCD. Portanto, se faz necessário conhecer como é realizado o trabalho a nível municipal (onde são efetuadas as medidas e realizadas a maioria das ações), para que dessa forma os métodos utilizados para o combate à doença possam ser avaliados bem como a própria política, proporcionando seu desenvolvimento e aprimoramento.

O município de Comendador Levy Gasparian é situado na microrregião sul fluminense do estado do Rio de Janeiro, com 8.183habitantes (IBGE) ${ }^{1}$ e no ano de 2013 figurou entre os mais afetados pela epidemia de dengue ocorrida no estado ${ }^{2}$. Considerando a responsabilidade do poder público em combater a doença, surge o questionamento: como o trabalho de combate à dengue dentro do componente "controle vetorial" do PNCD é realizado no município de Comendador Levy Gasparian?

O presente trabalho tem o objetivo de alcançar um panorama político do combate à dengue realizada pelo município de Comendador Levy Gasparian de 2009 a Abril de 2015, descrevendo a forma de trabalho adotada e os resultados alcançados pela política. Além disso, pretende-se levantar e analisar dados sobre a atual situação da doença no município, bem como investigar quais foram os impactos da implementação da política; saber em que medida os objetivos do programa vêm sendo alcançados e com base nos resultados encontrados, sugerir ações que complementem e contribuam com o trabalho já realizado.

A necessidade de se avaliar a política pública de combate à dengue se comprova pela gravidade da última epidemia ocorrida em 2013, na qual o município figurou entre os que apresentaram maior número de $\operatorname{casos}^{3}$, o que constitui um problema de grandes proporções para a saúde pública municipal.

Para toda política implementada é primordial aos formuladores conhecer o modo de funcionamento da máquina estatal, e de que forma a realidade anterior à política está sendo transformada, bem como a maneira que os diversos atores e setores vêm sendo impactados. Dessa forma, se faz necessário conhecer como o setor público vem respondendo à necessidade de combate à dengue e em que medida suas ações têm influenciado, impactado e transformado a realidade da população, sendo essa pesquisa uma contribuição não apenas ao trabalho dos formuladores de políticas, mas também uma contribuição teórica ao campo de administração pública. 
Com a presente pesquisa se espera alcançar um panorama da situação da política de combate à dengue realizada pelo município de Comendador Levy Gasparian do ano de 2009 a Abril de 2015 e conhecer seus impactos, destacando os resultados alcançados, dificuldades encontradas e sugerir maneiras de contornar as possíveis deficiências encontradas.

\section{Fundamentação teórica}

\subsection{Dengue: Características principais}

\subsubsection{Vetor, desenvolvimento e transmissão}

Causada por um vírus, a dengue tem dois tipos de transmissor: os mosquitos Aedes aegypti, (que também transmite a febre amarela) e Aedes albopictus, que por não possuir característica domiciliar, não é expressivo na transmissão da doença. Medindo menos de um centímetro, o Aedes aegypti é preto com listras brancas, sua picada não doi nem coça, e seu período de maior atividade é nas primeiras horas da manhã e no fim da tarde. Vive em torno de 45 dias, passando pelas fases de ovo, larva, pupa e adulto, que é o momento em que para nutrir os ovos, a fêmea do mosquito se alimenta de sangue que, se estiver contaminado com o vírus da dengue, torna a fêmea capaz de transmiti-lo (SILVA, 2008).

Para que os ovos se desenvolvam em larvas ( 2 a 3 dias), é necessário que sejam depositados em locais úmidos e quentes próximos à linha d'água, todavia em caso de períodos de ressecamento, os ovos podem tornar-se resistentes e permanecer viáveis por até um ano, uma adaptação que muito dificulta a eliminação do mosquito. A larva completa seu desenvolvimento em cerca de 5 dias e torna-se pupa, fase que precede a forma adulta. O processo do desenvolvimento de ovo a adulto leva em média 10 dias, e em cerca de dois dias, o mosquito adulto está apto a acasalar e continuar o ciclo de postura de novos ovos (SILVA, 2008).

\subsubsection{Problema de saúde pública}

O vírus causador da dengue é um arbovírus (transmitido exclusivamente por artrópodes) da família Flaviviridae com quatro sorotipos infectantes conhecidos: DEN1, DEN-2, DEN-3 e DEN-4 que podem se manifestar na forma clássica, com sintomas mais brandos ou na forma hemorrágica, mais grave e relacionada à infecção por um sorotipo diferente, visto que só é possível se infectar com um sorotipo uma única vez ${ }^{4}$. É observada uma sazonalidade das infecções no Brasil, com período de incidência maior nos primeiros meses do ano, pico entre março e maio seguido de uma queda brusca em junho (devido às baixas temperaturas e redução da umidade).

Devido à incidência de viroses benignas, vistas pela população como doenças simples que não necessitam de atenção médica, a subnotificação de casos de dengue é expressiva, significando que o número real de casos é ainda maior do que a saúde 
pública tem registrado (Teixeira, Barreto e Guerra, 1999), o que somado à morbidade, mortalidade e fatores como crescimento populacional desordenado, condições inadequadas de saneamento e baixa escolaridade da população torna imperativa uma ação do poder público no sentido de compreender melhor as estratégias utilizadas e buscar novas soluções para o combate à doença (FERREIRA B. J. et al., 2009) .

De acordo com Teixeira, Barreto e Guerra (2009), os principais fatores que determinam e facilitam a infestação do mosquito estão relacionados à organização dos espaços geográficos urbanos, o modo de vida da população e seus reflexos no ambiente, que criam as condições para a proliferação do vetor. Más condições socioeconômicas e adensamentos populacionais estão relacionados a uma maior capacidade de reprodução do mosquito e dispersão do vírus, comprovado pelo número predominante de criadouros encontrados em recipientes utilizados para armazenar água para consumo.

\subsection{Caracterização do Programa Nacional de Combate à Dengue}

\subsubsection{Características e objetivos}

Com o principal objetivo de erradicar a dengue, o Ministério da Saúde criou em 1996 o Plano de Erradicação do Aedes aegypti (PEA) que se dividia em nove componentes, contando com "operações de campo de combate ao vetor"; "informação, educação e comunicação social" e "vigilância epidemiológica e sistema de informação". O plano não foi capaz de cumprir seu objetivo devido principalmente à orientação à erradicação e ao grande número de depósitos acumuladores de água, que facilitavam a dispersão do vetor.

O aumento de casos de dengue no período de 1996 a 2001 fez com que o plano inicial fosse revisado, surgindo então o Plano de Intensificação das Ações de Controle da Dengue (PIACD) baseado na universalidade regional, sincronização e continuidade das ações. Esse plano definiu regiões geográficas de ação com financiamento estadual e municipal e gestão descentralizada e intersetorial. Em 2002, seguindo esses pressupostos e considerando a necessidade de ações constantes de controle e combate ao vetor, com resultados esperados em longo prazo, é criado o Programa Nacional de Controle da Dengue para reduzir a infestação por Aedes aegypti, a incidência e a letalidade da dengue e o índice de infestação predial (BRASIL, 2009).

Os objetivos específicos do PNCD incluem a organização das ações de prevenção e controle da dengue, a padronização dos insumos necessários, a definição de estratégias para redução da força de transmissão da doença através do controle do vetor e de seus criadouros, a capacitação da força de trabalho e gestores e aspectos como fortalecimento da articulação intersetorial, visando a integralidade das ações para o enfrentamento da dengue (BRASIL, 2009).

O PNCD é composto pela vigilância epidemiológica; combate ao vetor (onde se insere o PMCD); assistência aos pacientes; integração com a atenção básica (e com o SUS); ações de saneamento ambiental; ações integradas de educação em saúde; comunicação e mobilização social; capacitação de recursos humanos; legislação; 
sustentação político-social; acompanhamento e avaliação do programa, contando com sistemas de informação como o SINAN (Sistema Nacional de Agravos de Notificação) e Diagdengue, um banco de dados que permite acompanhar a implementação do programa nos municípios prioritários (FERREIRA B. J. et al, 2009). A gestão e ação do Programa Nacional de Combate à Dengue são realizadas a nível municipal, com apoio do estado e do Ministério da Saúde, sendo o financiamento responsabilidade federal (FIGUEIRÓ A.C. et AL; BRASIL, 2009).

As ações de combate à dengue do PNCD se baseiam em visitas diárias nas residências que visam identificar e remover os focos do mosquito e orientar os moradores quanto aos riscos de contaminação, campanhas, mutirões e trabalhos específicos de controle e veiculação de informação (BRASIL, 2009). No trabalho de prevenção é imprescindível a ação conjunta do poder público, órgãos de pesquisa e sociedade para evitar que o ciclo de contaminação e transmissão da doença se perpetue adotando medidas como manter tampadas caixas d'água, poços e cisternas, remover lixo que possa acumular água após as chuvas, utilizar químicos que eliminem larvas e ovos pela população e lavar recipientes que possam conter ovos do mosquito.

O controle e prevenção da dengue pelo PNCD podem ser realizados mecanicamente ao modificar os objetos que acumulam água para que isso não ocorra (eliminação) e quimicamente, com a aplicação focal de inseticida em locais que não se pode remover o depósito ou perifocal na superfície externa e interna de recipientes, dentro ou fora das residências para evitar a permanência do mosquito adulto e eclosão de novos indivíduos (BRASIL, 2009). A aplicação perifocal de inseticida é considerada polêmica em relação à eficácia por Teixeira, Barreto e Guerra (1999). O PNCD indica ainda a aplicação espacial de inseticidas de Ultra Baixo Volume (UBV) para redução da população da forma alada do mosquito em períodos de epidemia nas ruas com pulverizadoras montadas em veículos (“fumacê"), também considerada questionável em relação à efetividade pelos autores Teixeira, Barreto e Guerra, (1999).

Ações voltadas a situações de epidemias incluem a realização de mutirões de visitas domiciliares e aplicação de inseticida por meio de nebulização espacial a frio iniciando no local de ocorrência e abrangendo a área contida num raio de $150 \mathrm{~m}$ para tratar possíveis focos do mosquito transmissor (BRASIL, 2009). Contudo, para se antecipar a episódios epidêmicos, é necessário que o PNCD realize a detecção precoce de surtos, somada a ações de investigação e controle, monitorando o aumento no número de casos e agindo com antecipação (OMOTTO, SANTINI E ESTEVES, 2009). Uma forma de fazê-lo é através do Levantamento de Índice Rápido de Aedes aegypti, o LIRAa, que é um método de amostragem que tem como objetivo principal a obtenção de indicadores entomológicos de maneira rápida, fornecendo informações entomológicas em um período antecedente ao de maior transmissão, visando a identificação das áreas de maior risco (BRASIL, 2009).

\subsubsection{Desafios}

O programa de combate a dengue foi criado em resposta a um aumento na incidência de dengue no Brasil, e para que consiga alcançar o objetivo de reduzir o 
número de casos da doença, é imprescindível uma ação favorável da comunidade em relação às medidas lançadas pelo poder público. De acordo com Silva (2008) uma das maiores dificuldades enfrentadas pelas equipes de visitas diárias é o acesso às residências, seja por ausência dos moradores ou pela recusa desses às visitas, constituindo um impasse relevante, visto que grande parte dos recipientes focos do mosquito transmissor da dengue se encontra em ambiente residencial. Ainda de acordo com o autor, a mão de obra é escassa, refletindo o baixo investimento do poder público que se reflete nos ainda elevados números de casos registrados e eclosão de epidemias.

Essa opinião é compartilhada por Figueiró et al (2010) que afirma que o programa não tem alcançado os resultados esperados a despeito do tempo decorrido e recursos investidos, destacando a necessidade de avaliar a política. Para Ferreira et al (2009), os programas de combate a doenças baseados em controle químico que não contam com a participação da população, valorização, integração setorial e recursos de análise epidemiológica não podem obter sucesso.

Assim, percebe-se que a opinião dos autores converge à necessidade de participação da população de maneira a complementar e facilitar o trabalho público, bem como a correta realização do controle químico somado à devida valorização do programa e investimento por parte dos órgãos públicos responsáveis.

\section{Método de pesquisa}

\subsection{Definição da pesquisa}

A pesquisa é aplicada, uma vez que gera dados e informações que podem ser aplicados na resolução de problemas, envolvendo verdades e interesses locais e significando uma contribuição a outras realidades. Ao interpretar fenômenos e coletar dados não quantificáveis do ambiente natural, utilizando citações das pessoas acerca de suas experiências e pensamentos a pesquisa se caracteriza como qualitativa e considerando que é conduzida por dados que remetam a eventos já ocorridos que não podem ser controlados, a pesquisa é classificada como ex post facto (MORESI, 2003).

Devido ao foco no processo e seu significado, fazendo a exposição de características de determinado fenômeno e definição dos fatores que contribuem para que ocorra, se trata de uma pesquisa descritiva. Por ser realizada no local onde o fenômeno ocorre, pode ser classificada como pesquisa de campo, também como telematizada, pois se utiliza de ferramentas online e telecomunicações e documental por utilizar arquivos municipais e bibliográfica e se basear em material publicado em livros, artigos e teses acessível ao público (MORESI, 2003).

A população em que o trabalho será realizado é o Estado do Rio de Janeiro que se encontra debaixo das políticas nacionais de combate à dengue e a amostra não probabilística e selecionada por acessibilidade é o município de Comendador Levy Gasparian, executor da política. 


\subsection{Etapas da pesquisa}

Inicialmente, foram coletados dados junto ao município através de pesquisa documental e solicitação de informações dos responsáveis pelo programa municipal e vigilâncias sobre os índices e demais dados relevantes produzidos e utilizados para as ações de combate à dengue.

Em seguida, foi aplicado um roteiro fechado de entrevista semi-estruturada direcionado àqueles que efetuam as ações do programa visando conhecer seus métodos e rotinas de trabalho, quais equipamentos e materiais utilizam, o que conhecem sobre a política desenvolvida e como a avaliam, as maiores dificuldades que encontram e os avanços que julgam ter alcançado com o trabalho que realizam.

De posse dos dados, se procedeu a análise com base no método da paráfrase das ciências sociais ou hermenêutica que é uma interpretação da opinião colhida levando em conta a perspectiva do entrevistado de maneira subjetiva e resumida. Esse método é mais utilizado em material transcrito, principalmente de entrevistas abertas e pouco estruturadas, constituindo uma análise detalhada e segura do material ${ }^{5}$.

Utilizando a paráfrase que é uma formulação no lugar do material original, recorrendo a mais de um ponto de vista (entrevistado) para chegar a melhores interpretações do fenômeno, o primeiro passo é a realização da entrevista em si com abertura para solicitação de esclarecimentos e possíveis debates com o entrevistado, seguido do segundo passo que consiste na análise crítica das informações recolhidas, sistematizando e avaliando as teorias e definições fornecidas. Logo após, no terceiro passo, são identificadas as informações centrais em cada depoimento obtido, com posterior pedido de confirmação do próprio entrevistado se concorda com o resultado 5 .

Assim, a política realizada no município de Comendador Levy Gasparian foi caracterizada e descrita, averiguando se as ações realizadas estão de acordo com o proposto pelo PNCD, apontando os resultados que vem alcançando, se está atingindo os objetivos propostos e as principais dificuldades que enfrenta.

\section{Análise dos resultados}

\subsection{Apresentação e análise de dados}

A necessidade de um programa de combate à dengue e intensiva vigilância epidemiológica no município de Comendador Levy Gasparian se deve ao fato de o município fazer divisa com o estado de Minas Gerais e à proximidade a outras regiões que normalmente apresentam muitos casos de dengue. Devido a essa localização, existe grande fluxo turístico e deslocamento de trabalhadores que atravessam a região, aumentando o risco de casos da doença no município. Somado a isso, existe o comportamento desfavorável da população que pouco executa a prevenção, favorecendo a existência de criadouros do mosquito transmissor da dengue (PLANO..., 2014).

Dessa forma, o desenvolvimento de políticas públicas em saúde deve levar as diretrizes formuladas, os objetivos pactuados e métodos à realidade e às necessidades do 
nível municipal, o que se traduz no Plano municipal de contingência para assistência a pacientes com dengue. Na versão consultada encontram-se as justificativas para a realização do combate à dengue no município, as metas a ser alcançadas pelas vigilâncias (incluindo o componente "combate ao vetor") e pela rede de assistência ao paciente, capacitação de recursos humanos e ações a ser adotadas em período de contingência ${ }^{3}$. O Plano inclui indicadores de incidência de dengue, IIP $^{4}$, números de casos registrados e confirmados, internações e demais dados epidemiológicos e infraestruturais do município (PLANO..., 2014).

Com 4841 imóveis (PLANO..., 2014), o município de Comendador Levy Gasparian atualmente se situa dentro do Estrato II (não infestado) de acordo com as diretrizes nacionais, visto que passaram-se 12 meses sem a detecção do vetor (IIP igual a 0). Dessa forma, o município foi considerado "prioritário" 5 apenas até o ano de 2013, quando houveram índices de infestação predial maiores que 0 .

Para levantar dados foram entrevistados 5 agentes de endemias (cada agente é responsável por uma área, de preferência próxima a sua residência), um operador e um auxiliar serviços especiais (aplicação perifocal de larvicida com bomba "Hudson" (costal) e espacial com canhão pulverizador para $\mathrm{UBV}^{6}$, entrega de raticidas e coberturas de caixa d'água para a população e realização de visitas a pontos estratégicos ${ }^{7}$ ) e o biólogo responsável pelas análises entomológicas do PMCD (técnico em saúde). Os agentes estão distribuídos de acordo com a diretriz nacional, e possuem os equipamentos e materiais básicos que necessitam para realizar seu trabalho, mesmo que tenha sido relatada a necessidade de receber protetor solar.

O programa preconiza a realização de pesquisa larvária em visitas quinzenais a pontos estratégicos, atividades de comunicação e educação à população sobre prevenção e controle da dengue, realização de levantamento de índices em ciclos quadrimestrais (VD) para ambos os estratos ${ }^{8}$ e de pesquisa larvária amostral através do LIRAa e

\footnotetext{
${ }^{3}$ Ações adicionais ao trabalho de rotina executadas em situações que comprometam sua realização (Ex: surtos e epidemias)

4Índice de Infestação Predial, obtido através das ações de Levantamento de índice rápido de Aedes aegypti, o LIRAa. O IIP é a relação expressa em porcentagem entre o número de imóveis positivos e o número de
}

imóveis pesquisados (BRASIL, 2009).

${ }^{5}$ Para adequar o termo utilizado pela diretriz nacional à fala dos entrevistados, será utilizado o termo "prioritário" como sinônimo de "infestado".

${ }^{6}$ UBV: Ultra Baixo Volume. Controle espacial do mosquito através de aspersão de inseticida com nebulizador acoplado a um veículo (fumacê) (BRASIL, 2009).

${ }^{7}$ São locais onde há concentração de depósitos do tipo preferencial para a desova da fêmea do Aedesaegypti ou especialmente vulneráveis à introdução do vetor (BRASIL, 2009).

${ }^{8}$ Estrato I: Municípios infestados. Estrato II: Municípios não infestados (BRASIL, 2009). 
realização de bloqueio apenas para o estrato I, bem como pesquisa entomológica com ovitrampas, larvitrampas e armadilhas para o estrato II (BRASIL, 2009). De acordo com o Plano de contingência 2014/2015 o município deve realizar ainda a integração intersetorial, cobertura de $80 \%$ do total de imóveis do município e atualização do sistema de informação (RH-Dengue). As entrevistas revelaram que tais ações são executadas de forma regular, exceto a integração intersetorial, pesquisa entomológica e ações diferenciais de educação em saúde.

Em momentos de contingência, é determinado pelo PNCD que haja monitoramento do número de notificações através do banco de dados do SINAN e em caso de notificação (e classificação como estrato I), o PMCD deve realizar ações de bloqueio. De acordo com os entrevistados, tais ações são realizadas quando necessário, porém, devido ao baixo número de casos normalmente encontrado no município não é comum haver necessidade de fazê-lo.

Os dados obtidos se dividem em três categorias: "Conhecimento e execução da política do PNCD", "Resultados alcançados pela política na opinião dos que a desenvolvem" e "Avaliação da política municipal pelos que a desenvolvem", e a partir dessas categorias, as respostas obtidas podem ser agrupadas.

Dentro da primeira categoria, os entrevistados apontaram que as principais dificuldades que encontram são a resistência dos moradores às solicitações de remoção de focos do mosquito, tratamento e eliminação de possíveis criadouros do mosquito, incluindo reclamações sobre a periodicidade das visitas (muito freqüentes), recusa em recebê-los e a falta de consciência por parte da população da importância de atitudes de prevenção. Foram citados os imóveis fechados ou vazios, bem como locais de difícil acesso, seja em relação às estradas (áreas rurais), meios de transporte ou natureza do local (grande quantidade de entulhos, vegetação cerrada) a baixa remuneração, que causa desmotivação, a falta de recurso municipal e troca constante de funcionários.

Os entrevistados demonstraram ter em maioria apenas conhecimentos básicos sobre a política nacional, mesmo que cada um saiba desempenhar corretamente suas funções e saiba superficialmente as metas da política a ser executada, o que se deve principalmente à falta de treinamento teórico já que cada agente recebeu treinamento "horizontal" (de agente para agente) ou do próprio coordenador. Houve alguma dificuldade de relacionar o trabalho de combate à dengue à palavra "política". Em relação ao transmissor da dengue e ao vírus causador da doença, os entrevistados apresentaram um nível satisfatório de informação sabendo explicar o ciclo de vida, hábitos e características do mosquito, sorotipos e os principais sintomas da doença, devido principalmente a formação pessoal não relacionada ao programa municipal (agentes de endemias e técnico em saúde).

Dentro da categoria "Resultados alcançados pela política na opinião dos que a desenvolvem", os resultados na opinião dos entrevistados são que a população se tornou mais consciente da necessidade de eliminar e tratar focos do mosquito constituindo a maioria dos moradores aqueles que contribuem com o trabalho municipal, mesmo que ainda haja uma parcela da população que resiste a adotar medidas preventivas. Os entrevistados apontaram em maioria um impacto neutro da política devido a esse fator. 
Para a maioria os entrevistados os objetivos da política vêm sendo alcançados, o que é "comprovado" pelo baixo número ou nenhum caso da doença registrado no município em períodos que não há epidemia (Figura 1), relacionando a boa qualidade do trabalho ao baixo número de casos existentes. Foi apontada também a existência de casos de dengue como algo independente à realização do trabalho de combate ao vetor. De maneira geral, os objetivos de redução no número de casos e da mortalidade por dengue propostos pelo programa nacional vêm sendo alcançados e as ações referentes aos agentes vêm sendo cumpridas, excetuando-se a pesquisa entomológica com armadilhas e a capacitação dos profissionais de saúde responsáveis pelo controle do vetor.

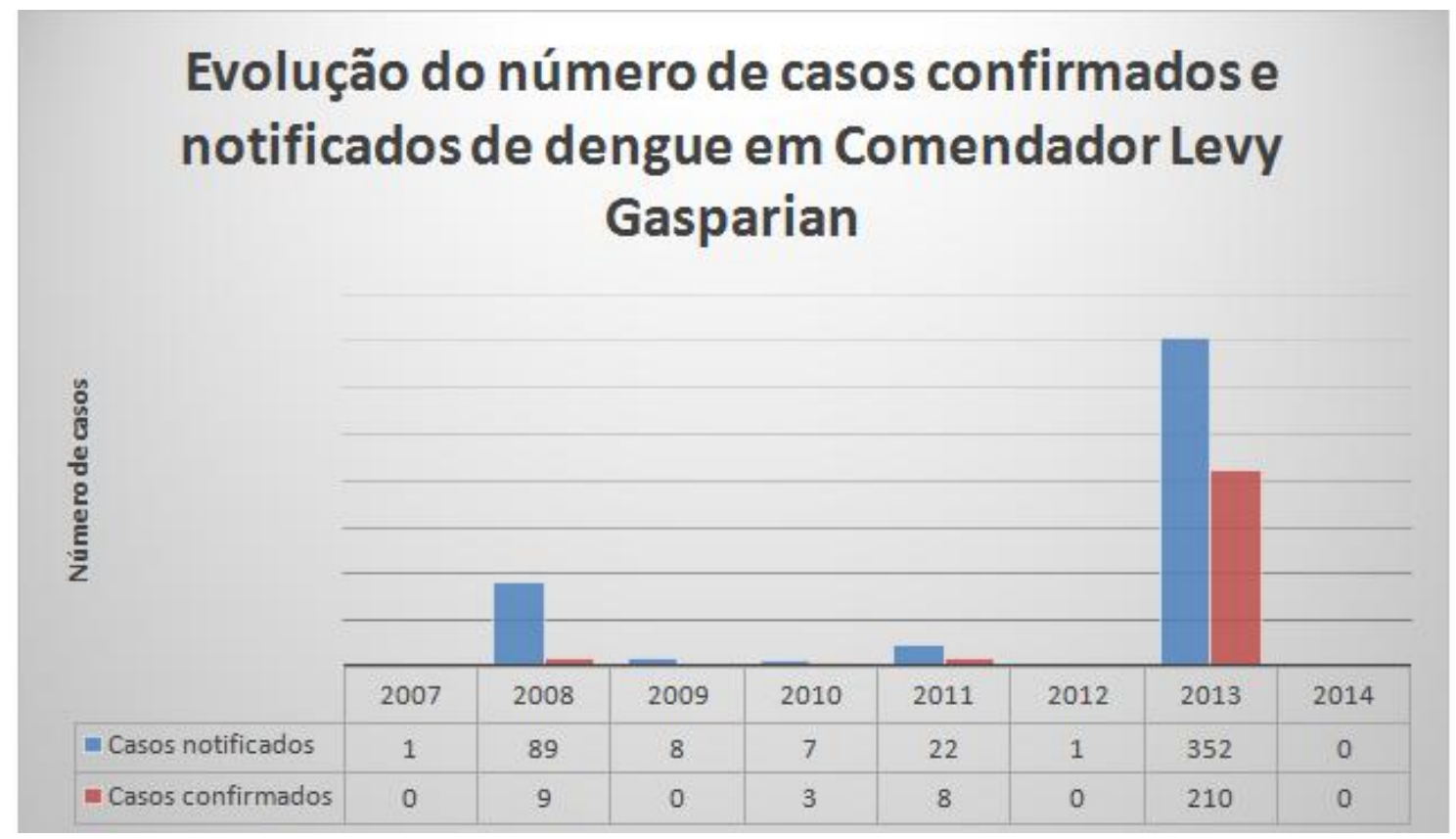

Figura 1: Evolução do número de casos confirmados e notificados de dengue em Comendador Levy Gasparian (PLANO...,2014)

Dentro da categoria "Avaliação da política municipal pelos que a desenvolvem" a avaliação geral da política foi positiva, sendo destacados pontos como a necessidade de adequação dos métodos municipais às diretrizes nacionais (treinamento), e a realização de um trabalho menos político (visibilidade) e mais técnico. Houve uma avaliação negativa, relacionada à necessidade de adoção de ações diferenciais de combate ao vetor. Foram sugeridas a aplicação de multas, notificações ou formas de "punição" aos moradores que mantém focos do mosquito ou possíveis criadouros em suas residências como forma de responsabilização e alerta à parte da população que resiste em adotar medidas preventivas prejudicando a realização do trabalho e a necessidade de maior incentivo estadual/ governamental aos municípios não prioritários na PNCD no sentido de suporte, acompanhamento, realização de treinamentos e bonificações. 


\subsection{Visão global}

Dentro da primeira categoria: Conhecimento e execução da política do PNCD pode-se perceber que mesmo com uma boa base sobre a parte biológica do combate ao vetor, falta aos agentes conhecer melhor as diretrizes da política, já que apesar de executarem os métodos e rotinas de forma adequada, conforme Omotto, Santini e Esteves (2009) que também constataram essa situação em seu trabalho, é importante àquele que executa a política entender a missão e a essência daquilo que faz, e dessa forma planejar e avaliar suas ações, adequando-as às limitações e possibilidades.

Ainda nessa categoria, as principais dificuldades encontradas na execução das atividades concordam com o trabalho de Silva (2008) ao apontar a falta de acesso às residências, recusas e imóveis vazios como fatores que prejudicam o trabalho, já que grande parte dos criadouros se encontra em residências e a reprodução do mosquito ocorre em qualquer recipiente, constituindo uma barreira para o controle.

A segunda categoria revelou que grande parte da população vem se tornando mais consciente da importância do combate a dengue, confirmando o que diz Figueiró et al (2010) ao afirmar que na verdade a população é informada sobre a questão, demonstrando que a informação é disseminada, porém tem pouco impacto sobre o comportamento preventivo das pessoas. $\mathrm{O}$ autor afirma que aqueles que não adotam medidas de combate ao vetor da dengue delegam ao poder público tais ações, associando a visão negativa que têm da esfera pública com a falta de priorização dessas medidas e com a crença de que a doença tem caráter inevitável, o que de acordo com os entrevistados também acontece no município.

Os impactos e resultados obtidos pela política se relacionam, na opinião da maioria dos entrevistados à conscientização de parte da população e ao baixo número de casos encontrados, porém, para Figueiró et al (2010), resultados positivos em relação a índices da doença não podem ser relacionados à atuação do programa, devendo ser ligados a ocorrência de epidemias anteriores e esgotamento de indivíduos susceptíveis a contrair a doença. Mesma opinião têm Teixeira, Barreto e Guerra (1999) que atribuem a dinâmica das populações do mosquito, a organização dos espaços geográficos e as características dos vírus circulantes (virulência, diferenças genéticas) a um baixo número de casos, mas destacam que as ações de combate ao vetor não devem ser negligenciadas. Ainda de acordo com os autores, um fator que influencia no número de casos é a subnotificação, tornando os registros oficiais um número subestimado.

A categoria "Avaliação da política municipal pelos que a desenvolvem" demonstrou a necessidade de "adequar a prática à teoria", que pode ser interpretado como necessidade de capacitação, o que na opinião de Figueiró et al (2010) é essencial e na opinião de Silva (2008) está relacionado diretamente a falta de controle do vírus.Também foi constatada a necessidade de realização de atividades de educação em saúde, o que para Silva (2008) causaria maior sensibilização na população. Ainda nessa categoria, foi sugerida uma maior integração e suporte do poder público em relação ao programa municipal, fator que de acordo com Figueiró et al (2010)faz parte de medidas que tornam as ações de controle mais efetivas e mais eficientes concordando com Silva (2008). 


\section{Conclusão}

O presente estudo pôde atingir seu objetivo de analisar a política de combate à dengue no município de Comendador Levy Gasparian e diante do exposto, pode-se concluir que a política realizada no município de Comendador Levy Gasparian é orientada pelo Plano municipal de contingência que contém as diretrizes nacionais para a execução das atividades que incluem levantamento de índices de infestação durante os ciclos de visitas diárias, visitas a pontos estratégicos, tratamento químico de depósitos e criadouros do mosquito, realização de ações de bloqueio e medidas a ser adotadas em caso de epidemias.

Com a pesquisa realizada foi possível conhecer como a política é desenvolvida e concluir que os objetivos propostos pelo PNCD vêm sendo alcançados. Foi possível delimitar os resultados alcançados pela política bem como os impactos causados e a partir da opinião dos entrevistados e dos dados levantados, sugerir diferentes medidas para complementar as ações já realizadas.

Dentre os dados obtidos destacam-se as principais dificuldades encontradas que também foram apontadas por Silva (2008) e Figueiró et al (2010), como a falta de capacitação dos profissionais que foi destacada como fator que precisa ter mais atenção do poder público e os principais resultados obtidos com a implementação da política, onde figura a maior conscientização da população apesar de ainda haver necessidade de divulgar informação de qualidade e de realização de mais ações de educação em saúde, para que a parcela indiferente da população se sensibilize. Foi constatado que parte dos entrevistados relaciona o pequeno número de casos da doença ao trabalho municipal, o que de acordo com Figueiró et al (2010) e Teixeira, Barreto e Guerra (1999) deve ser atribuído a fatores populacionais e biológicos, sem descartar a importância do trabalho de combate ao vetor.

Contribuindo para a execução de outros trabalhos e levantando pontos ainda a ser explorados, esta pesquisa evidencia a necessidade de averiguar e conhecer melhor até que ponto as dificuldades encontradas e apontadas podem influenciar os resultados obtidos pela política e impedir de alcançar as metas e como tais dificuldades podem ser contornadas e, além disso, como são realizadas as medidas de controle químico, sua adequação à preconização do PNCD e eficácia no controle de populações de mosquitos.

\section{Referências bibliográficas}

- Prefeitura de Comendador Levy Gasparian, Secretaria de saúde, Plano municipal de contingência para assistência de pacientes com dengue, Rio de Janeiro, 2014

Braga, I. A. , Valle, D. , Aedes aegypti: histórico do controle no Brasil. Artigo de revisão, Epidemiologia e Serviços de Saúde. 2007; 16(2) : 113, abr/jun de 2007 a

Braga, I. A., Valle, D., Aedes aegypti: inseticidas, mecanismos de ação e resistência. Artigo de revisão. Epidemiol. Serv. Saúde, Brasília,16(4):279-293, out-dez, 2007 b 
Brasil. Fundação Nacional de Saúde. Manual de saneamento. 3. ed. rev. - Brasília: Fundação Nacional de Saúde, 2006

Brasil. Ministério da Saúde. Secretaria de Vigilância em Saúde. Departamento de Vigilância Epidemiológica.Diretrizes nacionais para prevenção e controle de epidemias de dengue / Ministério da Saúde, Secretaria de Vigilância em Saúde, Departamento de Vigilância Epidemiológica. - Brasília : Ministério da Saúde, 2009

Ferreira, B. J. et al, Evolução histórica dos programas de prevenção e controle da dengue no Brasil, Ciência \& Saúde Coletiva, 14(3):961-972, 2009

Figueiró, A. C.; Sóter, A. P.; Braga, C.; Hartz, Z. M. de A.; Samico, I., Análise da lógica de intervenção do Programa Nacional de Controle da Dengue, Rev. bras. saúde matern. infant;10(supl.1):s93s106, nov. 2010. tab.

Moresi, E. (Organizador). Metodologia da Pesquisa, Universidade Católica de Brasília - UCB, Pró-Reitoria de Pós-Graduação - PRPG, Pprograma de Pós-Graduação Stricto Sensu em Gestão do Conhecimento e Tecnologia da Informação, Brasília- DF, Mar 2003

Omotto, C. A., Santini, S. M. L. , Esteves, J. L. M., CONTROLE DA DENGUE: UMA ANÁLISE DA IMPLEMENTAÇÃO DO PNCD E A RELAÇÃO DO PROCESSO DE TRABALHO NA 16a REGIONAL DE SAÚDE DE APUCARANA/PARANÁ - BRASIL, II Congresso Consad de Gestão Pública Painel 44: Gestão da saúde, PR, Brasil, 2009

Silva, J. S. ,A dengue no Brasil e as políticas de combate ao Aedes aegypti: da tentativa de erradicação às políticas de controle, Hygeia3(6):163-175, Jun/2008

Teixeira, M. G., Barreto, M. L., Guerra, Z.,Epidemiologia e Medidas de Prevenção do Dengue, Informe Epidemiológico do SUS 1999, 8(4):5-33., 1999

${ }^{1}$ IBGE,http://www.ibge.gov.br/home/estatistica/populacao/censo2010/tabelas_pdf/total_ populacao_rio_de_janeiro.pdf Visitado em 27/01/2015

${ }^{2}$ Levy Gasparian é a segunda cidade do estado com maior risco de dengue. Disponível em: http://www.revistaon.com.br/materias/12147/levy_gasparian_e_a segunda cidade do estado_com_maior_risco_de_dengue Visitado em 13/06/2014

${ }^{3}$ Levy Gasparian sai da lista de municípios com epidemia de dengue. Disponível em:

http://www.revistaon.com.br/materias/12392/levy_gasparian_sai_da_lista_de_municipi os_com_epidemia_de_dengue Visitado em 13/06/2014

${ }^{4} \mathrm{http}: / / \mathrm{www}$. eumed.net/rev/cccss/24/politicas-publicas-dengue.html Visitado em $17 / 02 / 2015$

${ }^{5}$ Técnicas de Análise qualitativa. Disponível em: http://www.cin.ufpe.br/ pcart/metodologia/pos/Mayring043.pdfVisitado em 27/02/2015 
